This is the peer reviewed version of the following article: Ruiz Castro, Mayra and Holvino, Evangelina (2016) Applying intersectionality in organizations : inequality markers, cultural scripts and advancement practices in a professional service firm. Gender, Work \& Organization, 23(3), pp. 328-347., which has been published in final form at http://dx.doi.org/10.1111/gwao.12129. This article may be used for non-commercial purposes in accordance with Wiley Terms and Conditions for SelfArchiving. 


\title{
Applying intersectionality in organizations: Inequality markers, cultural scripts and advancement practices in a professional service firm
}

\begin{abstract}
This paper presents an intersectional analysis of career advancement practices in professional service firms. It reveals how gender, class, racio-ethnicity and culture intersect at the individual, organizational and societal levels to create and reinforce advantages and disadvantages across complex dimensions of difference. Based on a qualitative analysis of data collected in a Big Four firm in Mexico, this article advances the empirical study of intersectionality in organizations by applying the construct of 'cultural scripts' and proposing the use of 'markers of inequality' to illuminate the simultaneous construction of differences of gender, class and racio-ethnicity in a specific socio-cultural context. Our findings show that career trajectories and advancement in this firm are contradictory processes, overdetermined by individual employee's lived identities, work interactions shaped by those identities, as well as formal and informal organizational practices embedded in an already raced, classed and gendered societal context and culture.
\end{abstract}

\section{Key words:}

Intersectionality in organizations; Inequality; Gender, Class and Racio-ethnicity; Culture; Big Four Firms 


\section{Introduction}

Research in professional service firms (PSFs) has primarily explored gender to study discrimination and inequality in this sector (Anderson-Gough at al., 2005; Broadbent \& Kirkham, 2008; Dambrin \& Lambert, 2008; Whiting, 2008; Jonnergård et al., 2010; Kornberger et al., 2010; Ruiz Castro, 2012; Windsor \& Auyeung, 2006). The gendered nature of the accounting profession, in particular the socialization into certain behaviors, attitudes and characteristics that construct 'the ideal worker' (Acker, 1990) and 'accountant as male' has been widely explored. Other social differences and dimensions of inequality, including class, race and ethnicity, have yet to receive wider attention. These social categories are mostly treated as isolated dimensions, where their mutually constitutive effects such as how gender is raced and classed are overlooked (Acker, 2006b; Holvino, 2012).

Furthermore, most research on career advancement, discrimination and inequality in accounting and professional organizations has mainly focused on understanding the experiences of women, and more specifically, white western women (Hammond, 2003), with only a few studies focusing on Latin America and the Caribbean islands (Annisette, 2003; Ruiz Castro, 2012). Therefore, we still know little about the ways in which different manifestations of inequality intersect and how those intersections are mediated by culture in specific socio-cultural contexts, especially as professions globalize and impact developing economies (Muzio and Tomlinson, 2012).

Considering the numerous contributions of intersectionality in other fields of study and the recent calls to bring intersectionality into organization studies and the field of work (Holvino, 2010b; McBride et al., 2015; Nkomo and Stewart, 2006; Calás et al., 2014; Styhre and Eriksson-Zetterquist, 2008; Zander et al., 2010), this neglect presents a major limitation for understanding organizational inequality in PSFs (Muzio and Tomlinson, 2012).

In the context of Mexico, intersectionality as a research approach has yet to gain attention, particularly in the study of organizations. Much of the research conducted has focused on maquiladoras, or export zone factories along the US-Mexican border, and while it makes visible the intersections of gender, class, ethnicity and nationality (Fernández-Kelly, 2004, 2005, 2008; Villarreal and Yu, 2007), it does not explicitly use an intersectionality framework. In addition, its influence in mainstream organizational research appears limited.

To contribute to filling this gap, this paper explores the intersections of gender, class, racio-ethnicity and culture at the individual, organizational and societal levels and how these intersections construct and reinforce unequal career opportunities in organizations. Focusing on PSFs and the Mexican context, we draw on qualitative data collected at an accounting Big 
Four firm in Mexico. We use the reconceptualization of intersectionality as 'simultaneity' proposed by Holvino (2010b, 2012) and the constructs of 'markers of inequality' (Antonucci et al., 2011) and 'cultural scripts' (Dhingra, 2007; Holvino, 2010a). In this application, we identify the specific ways in which differences of gender, class and racio-ethnicity are constructed as important in this PSF through employees and managers' discourses and interactions. We also analyze how these individual constructions implicitly and explicitly intersect with organizational practices of career advancement and with national-societal discourses of differences. The paper offers specific understandings about the practices of advancement and inequality in a Big Four firm in Mexico as well as methodological insights into the use of intersectionality in empirical research in organizations.

The paper is organized as follows: In the first section we present the theoretical and conceptual framing for our intersectional work. We then expand on the methodology and analytical framework employed. In the third section, we illustrate and discuss our findings, that is, the specific forms of privilege and disadvantage in advancement practices in this firm. The final section presents the conclusions and discusses theoretical, methodological and practical implications of our findings.

\section{The intersectional study of inequality in organizations}

Intersectionality is a way of thinking that understands gender, race, ethnicity, class, sexuality, religion and other categories of social difference as interlocking and mutually constitutive at the micro level of individual experience and at the macro level of institutional and societal structures and cultural ideologies. These intersections are understood as relations of power - privilege and disadvantage - that result in complex inequalities, which are more than the analysis of any one category by itself or the mere sum of various categories (Collins, 2000, 2015; Cho et al., 2013; Crenshaw, 1989; Davis, 2008; Knudsen, 2006; Valentine, 2007; Weber, 2010).

Intersectionality has been lauded as one of the most important developments in feminism and gender studies today (Davis, 2008; McCall, 2005). The application of intersectionality has resulted in new insights in many disciplines and, in the last few years, the call to bring intersectional analyses to organization studies has increased (Banerjee, 2010; Holvino, 2010b; McBride et al., 2015; Styhre and Eriksson-Zetterquist, 2008; Zander et al., 2010). In their Special Issue editorial on researching gender in PSFs, Muzio and Tomlinson 
(2012) specifically call for placing "greater attention ...on the importance of intersectionality and the ways in which gender relates to other sources of inequality" (p. 463).

Empirical studies of intersectionality in organizations are growing, yet, the majority address the construction of identities/subjectivities and the relationship between social and work identities (Atewologun and Sealy, 2014; Bell and Nkomo, 2003; Boogaard and Roggeband, 2010; Fearfull and Kamenou, 2006; Kelan, 2014). As useful as these analyses are, their emphasis on identity intersections results in an under-theorization and underexploration of the intersections and co-reproduction of identity with macro societal and institutional practices, a key element of intersectionality theory. Consequently, the broader social justice change agenda of intersectionality theory gets easily lost with a focus on individual identities and experience (Collins, 2015; cf. Healy et al., 2011). In this paper, we use Holvino's reconceptualization of the intersectionality of social differences as "the simultaneity of identities, organizational and societal practices," developed for the study of inequality in organizations (Holvino, 2010b). Holvino proposes that race, gender, class, ethnicity, sexuality, and nation be studied as simultaneous processes of identity (how individuals see themselves and are perceived by others in organizations), institutional processes (organizational structures and procedures that are taken for granted, but perpetuate inequalities), and societal practices (local and global cultural influences and structures) in which organizational practices are embedded (Holvino, 2010b). Similarly to Acker's ‘inequality regimes' (2006b) and Winker and Degele's 'multi-level analysis' (2011), 'simultaneity' brings attention to 'organizations' as a major site where inequalities are created and reproduced, seeking to illuminate the complex interactions between individual identity, societal structures, and organizational and cultural practices (Bowleg, 2012; Holvino, 2003). This approach to intersectional research in organizations helps shift the focus of many current studies from the relation between identities and work to the relations between identities, organizational and societal-structural practices and how they create fluid, complex and contradictory systemic inequalities (Holvino, 2012; Hulko, 2009; Purkayastha, 2012).

In this paper, we deviate from the inter-categorical, intra-categorical and anticategorical approaches to research (Choo and Ferree, 2010; McCall, 2005) and instead illuminate the construction of intersectional inequality in the systemic practices and discourses of organizations where we seek to "identif[y] and untangl[e] the differential and material impact of everyday practices in organizations" (Holvino, 2010b, p. 264).

To this end, we draw from Acker's study of 'inequality regimes' (2006b, 2011). Acker defines inequality regimes, as "the systematic disparities ... in control over 
organizational goals and outcomes... decisions... opportunities, pleasures of the work, and respect and freedom from harassment" among different organizational participants (Acker, 2006a, p. 110). Acker suggests identifying the various components of the inequality regimes that can be observed in an organization. These include the social differences that serve as the bases of inequality; the processes and practices that create, maintain or challenge inequality; the visibility and legitimacy of inequalities; the mechanisms of control and compliance that sustain them, and the competing/contradictory interests which maintain or challenge inequalities (Acker, 2011, p. 70).

In this study, we focus on the processes and practices of advancement and promotion and on the intersections of gender, racio-ethnicity and class, which serve as the bases for the creation and reproduction of inequalities. Given our intersectional approach, we understand social differences as social processes of differentiation and social constructions that get reified and attached to groups and people, which constitute relations of power but are not essential aspects or inherent characteristics of being. Though intersectionality refers to the interactions of differences such as gender, racio-ethnicity and class, we clarify what we mean by these differences as somewhat distinct from each other. Exploring these categories of social difference in the Mexican social and historical context alerts us to how these constructions might surface in our study.

By gender we mean differences constructed by markers based on a supposed binary of male and female, usually inseparable from sexuality and heteronormative norms, structures and processes (Pringle, 2008). Racio-ethnicity is understood as the social and cultural differences marked by color and phenotypical (race) and cultural, historical, and linguistic (ethnic) differences (Loury, 2009). Because distinct classifications of groups as racial or ethnic often lead to inaccuracies as the differences are not mutually exclusive, we use Cox's term of 'racio-ethnicity' throughout this paper (in Nkomo and Stewart, 2006, p. 534). Finally, by class we refer to differences constructed based on access to resources, symbols and other markers of economic power and status and the means of production and reproduction (Acker, 2011; Anthias, 2013).

In addition, inequality regimes are "culturally mediated, patterns of inequality maintained by particular policies, rules, conventional practices of organizing work, and ways in which people interact with each other" (Acker, 2011, p. 70). To help identify these "culturally mediated patterns of inequality" and the discursive and societal-cultural forces influencing organizational practices in Mexico, we use the construct of 'cultural scripts' (Dhingra, 2007; Holvino, 2010a). Cultural scripts are "commonly held assumptions about 
social interactions and communication - ways of thinking about what one can/cannot do or say - particular to a group" (Holvino, 2010a, p. 1). They serve as a 'tool kit' of knowledge, skills and symbols that help individuals address specific life problems (Dhingra, 2007). One advantage of exploring cultural differences and context using the concept of 'scripts' (Bowleg et al., 2004) is that 'scripts' are not stereotypes, nor do they try to present a group's culture as one-dimensional and fixed. Instead, cultural scripts can reflect the hybridity and fluidity of culture and identities, still referring to those aspects which are shared as "social norms" among members of a particular group (ibid., p. 70). The concept offers a way of capturing the complexity and simultaneity of identity and differences in organizations by acknowledging the influence of both culture and individual agency, where 'scripts' are nondeterministic and not universal, but can help us identify common interpretive backgrounds that members of the Big Four firm in Mexico use to construct and attach meaning to social differences and inequality.

\section{Research on differences and inequality in professional service firms}

In the study of inequality in PSFs gender has been used as the central category of analysis. Although some consideration has been given to racio-ethnicity and class in the study of the accounting profession, these dimensions of difference are seldom studied at their points of intersection and with consideration to the prevailing national and cultural processes in which they are embedded, as if organizational practices took place in a vacuum.

For example, only a handful of studies have specifically explored the influence of race and ethnicity on career advancement in the accounting profession (Hammond, 2003). The studies available were primarily published in the 1990s (Weisenfeld and Robinson-Backmon, 2001) and focused on African-Americans in public accounting in the US. More recent studies have demonstrated that people of color and ethnic minorities, particularly women of color and ethnic minority women, are persistently excluded from advancement opportunities and confined to the least powerful positions (Annisette, 2003; Giscombe, 2008; Kim, 2004). They also show the importance of race and ethnic heritage in promotion decisions and how these intertwine with the behavioral expectations put on specific racio-ethnic groups (Lowe et al., 2001). Overall, these studies point at the challenges of achieving success in a profession which is not only predominantly male, but is also white and middle-class (Annisette, 2003; 
Fearfull and Kamenou, 2006). Nevertheless, this research tends to focus on the comparison of groups of people classified by pre-defined categories of social differences.

The accounting literature has paid almost no attention to class structures and inequalities in the wider society and how these are (re)produced within accounting and PSFs. This might be partly because class differences are "hard to observe" (Jacobs, 2003, p. 570) among employees with seemingly similar educational backgrounds and professional conduct, participating in a high-social status and privileged profession (Brown, 1995). However, identities and symbols, divisions, and interactions embedded in specific contexts construct the unequal class structures in organizations (Acker, 1992; Holvino, 2000; Scully and BlakeBeard, 2006). For example, the development (or lack) of generic or transferable skills in university education is one form in which class divisions are constructed in the accountancy profession (Jacobs, 2003). Similarly, called 'soft skills,' including leadership, written and oral English communication skills, are increasingly deemed decisive in hiring processes in accounting firms ( Jacobs, 2003; James and Otsuka, 2009; Kim, 2004; Law and Yuen, 2011), but these skills are likely to subtly favor middle-class applicants over applicants from working-class communities as they are linked to applicants' upbringing and "derive from cultural context, particularly that of the dominant or ruling classes" (Jacobs, 2003, p. 575).

Class symbols and identities are also constructed in organizations in relation to gender and racio-ethnicity by standards of physical appearance and professional dress and demeanor. Research has shown that dressing 'professionally' and being considered 'attractive' are influential factors in recruitment and advancement processes in the US and the UK (Anderson-Gough et al., 2005; Haynes, 2012). This poses a problem for the careers and identities of those individuals who do not respond to the norms of the profession, "if they are to secure equal access to status, career progression and affirmation" (Haynes, 2012, p. 504). Although the characteristics that deem individuals 'attractive' may vary according to the social context, light skin color and 'whiteness' are key features of beauty and worthiness (Annisette, 2003; Sue, 2006), particularly in a profession that seeks to maintain its privileged position in society (Portwood and Fielding, 1981).

In all, while research in PSFs has tackled directly or indirectly the social categories of gender, class and racio-ethnicity, to our knowledge there is no exploration of the intersection of these differences and their inequality effects. Therefore, studying how these intersecting differences operate as simultaneous processes of identity, organizational and societal practices, which create and sustain inequalities, could be of much value to the theory and research of PSFs. 


\section{Methodology}

\section{Background}

The data analyzed in this article was collected by the first author as part of a large-scale research project on gender and organizations in a Big Four accounting firm in Mexico City. The original case study focused on gendered organizational practices and their impact on people's work and private lives. Managers and staff from two core business areas (Auditing and Taxes) and two administrative areas (Business Development and Administration and Finance) were selected using a stratified random sampling method. A Human Resources representative sent an email to the selected group of employees introducing the study and the researcher. Thereafter, the researcher sent an email invitation to participate in a face-to-face interview. A total of 37 managers and staff members (19 women and 18 men) participated in this study (representing 55\% of all those invited to participate). To gain a deeper insight into the organizational context, including internal processes and policies, additional interviews were conducted with managers in the Human Resources department and data from an internal employee satisfaction survey, which included the theme of career advancement, were analyzed.

Semi-structured interviews of between 45 minutes and two hours were conducted in Spanish, recorded and transcribed. Interviews took place in private meeting rooms in the firm's premises. The demographic information of each respondent collected in the original case study included gender, age, marital and parental status.

\section{Secondary data analysis}

Intersectionality theory does not offer a universal methodology (Crenshaw, 2011). Instead, "multiple approaches to the study of intersectionality" are needed (McCall, 2005, p. 18), which are defined according to the inequality problem they aim to bring attention to and intervene on. Although the central category of analysis in the original study was gender, employees' lived experiences pointed at the many intersections of gender with class, racioethnicity and culture related to career advancement. Because the data represented a "good fit" to the research problem and the researchers' position (Walsh et al., 2015), a secondary analysis was carried out to identify these intersections. The secondary analysis involved the 
use of some of the methodologies recommended for intersectionality studies, including an organizational case study, in depth interviews, and micro-analytic readings of everyday practices (Phoenix and Pattynama, 2006; Simien, 2007). It also used contextual information (Van den Berg, 2008), including detailed transcriptions of complete interviews, details of participants' selection and interviewing process, and information about intervieweeinterviewer as well as interviewee-interviewee interactions, registered in the researcher's fieldwork diary. Furthermore, both authors are native Spanish speakers, which allowed them to analyze language subtleties that can get lost when qualitative data is translated into English. Acknowledging that there are ethical concerns in secondary analysis in relation to confidentiality and anonymity (Thomson et al., 2005), the author who conducted the interviews maintained confidentiality of the firm's and participants' names as originally agreed with them and this information remained confidential to the second author.

As mentioned earlier, since racio-ethnicity and class differences were not purposefully considered in the original data collection, participants were not categorized in this way, yet, our concern in this study was with the interpretation of data intersectionally and not as much with crafting specific questions to ensure that intersectional data on social categories were collected (Acker, 2012; Bowleg, 2008; Dhamoon, 2011; Hunting, 2014). Nevertheless, a secondary intersectional analysis of social differences was possible because the first author asked interviewees about their overall perceptions of and experiences with career advancement and discrimination, which opened the interview to other aspects of inequality beyond gender. Interviewees were also asked about their satisfaction with work/life balance and their strategies to deal with it, which disclosed many issues pertaining to class and racio-ethnicity. In addition, the first author kept a fieldwork diary that also provided relevant data on 'markers of inequality,' a construct we discuss next.

\section{Markers of inequality}

Whilst most of the empirical study of intersectionality relies on pre-given and supposedly universal categories of inequality such as race and gender, we did not draw solely on pre-determined categories to carry out our analysis. Instead we treated it as "an empirical exercise" to identify which differences or categories of differences were important to the complexity of inequalities in this particular organization (Zander et.al, 2010, p. 463). We use the construct of 'markers of inequality' (Antonucci et al., 2011) to refer to the specific indicators - physical, symbolic, discursive and structural - that get attached to particular differences to co-construct inequalities that result in differential outcomes in advancement 
opportunities. An emic approach that identified emergent categories of difference "as embedded in a specific time and place" (Tatli and Özbilgin, 2012, p. 180) was adopted in order to understand social categories and the intersectionality of differences within a particular socio-economic and cultural context and to stay away from pre-determined classificatory schemas of 'culture' (Calás, 1992; Townsend-Bell, 2011). We sought to identify what 'markers' or 'indicators' of gender, class and racio-ethnicity employees and managers constructed as important, through discourse, interactions and reported experience. In addition, we identified how these individual constructions, implicitly and explicitly, intersected with organizational practices of advancement and with cultural scripts that (re)created inequality in this firm in Mexico.

\section{Data coding}

The complete transcripts of thirty-nine interviews and the researcher's fieldwork diary, which included comments on the behavior and appearance of each interviewee, as well as the researcher's thoughts and feelings after the interviews, were revised and re-coded by the first author adopting a Grounded Theory approach of thematic analysis (Martin and Turner, 1986).

The objective of our analysis was to make markers of inequality visible in their simultaneity, even if participants did not make them visible, labeled or prioritized them (Kelan, 2014; Warner, 2008). Class markers were identified by paying attention to indicators of participants' socio-economic status such as the type of university attended, parents' occupation, residential location, household composition and arrangements, leisure activities and dress/appearance. In terms of racio-ethnicity, we used skin color as one of the markers of inequality that conveys status, privilege and disadvantage in the Mexican social structure (Gates, 2011; Villarreal, 2010). The first author was able to use participants' skin color as a category of analysis by recalling participants' faces, by systematically reviewing fieldwork diaries (where she frequently described people's appearance including adjectives like moreno $^{l}$ ), by looking back at the pictures she took of some of the participants ${ }^{2}$ and by noting participants' own description and stories about their own or their colleagues' skin color. Cultural scripts were identified in interviewees' comments of "this is how it works here" or

\footnotetext{
${ }^{1}$ Dark-skinned.

${ }^{2}$ The first author conducted more than 90 interviews in two different companies at the time. In order to be able to remember participants' faces, she took pictures of some of the participants.
} 
"people behave in this way," as well as drawing from the literature on national and racioethnic scripts such as respeto and compadrazgo (Holvino, 2010a; Lomnitz and Sheinbaum, 2004). Clearly, elements of gender, class, racio-ethnicity and culture overlapped. We did not intend to classify them or analyze them as single-axis but to identify how they seemed to operate simultaneously and in complex ways. Table 1.0 provides a simplified example of how data coding and analysis was conducted.

Table 1.0 Examples of identification and analysis of intersections

\begin{tabular}{|c|c|c|}
\hline Case & Data & Markers of inequality \\
\hline Martha & $\begin{array}{l}\text { What are the career perspectives you see within the firm? } \\
\text { Hmmm, I was very excited when I joined the firm, but I'm not } \\
\text { anymore... I think it's discrimination because I do not fit the desired } \\
\text { profile... People here are friendly, you receive training and support, but } \\
\text { I'm tagged on the basis of my profile. I'm } 30 \text { years old, married and } \\
\text { without the required proficiency of English. I lag behind in comparison } \\
\text { with people who are younger. } \\
\text { Note: Martha also talks extensively about the advantage of being pretty } \\
\text { in advancement opportunities, as discussed in the findings section. } \\
\text { Do you have any hobby or other activities besides work? } \\
\text { It takes me } 1.5 \text { hours to get home.... I live in [a low-income borough in } \\
\text { Mexico City]. I arrive at 9:00 pm, just to have dinner, wash the dishes } \\
\text { and sleep. }\end{array}$ & $\begin{array}{l}\text { Married } \\
\text { Older } \\
\text { English Proficiency } \\
\text { Appearance } \\
\text { Residential location \& } \\
\text { commute time } \\
\text { Household composition \& } \\
\text { arrangements } \\
\text { Use of free time }\end{array}$ \\
\hline Emilio & $\begin{array}{l}\text { Do you have other family responsibilities? } \\
\text { I started working and buying things for myself at a very young age } \\
\text { instead of asking my father for money.... My father participated in that } \\
\text { famous strike at [a Mexican beverages company] } 20 \text { years ago [the } \\
\text { company closed down and workers lost their jobs]. We were in misery. I } \\
\text { then started to work and run errands for money. } \\
\text { Note: Emilio also refers to experiences in relation to his dark-skin color } \\
\text { and the type of university he graduated from, as discussed in the } \\
\text { findings section. }\end{array}$ & $\begin{array}{l}\text { Parents' occupation } \\
\text { Household composition \& } \\
\text { arrangements } \\
\text { Type of university attended } \\
\text { Skin color }\end{array}$ \\
\hline
\end{tabular}




\begin{tabular}{|l|l|l|}
\hline Yazmin & $\begin{array}{l}\text { From fieldwork diary: } \\
\text { Brown-skinned color; attended [a public university] }\end{array}$ & $\begin{array}{l}\text { Do you have any hobby or other activities besides work? } \\
\text { We play golf on Sundays. We go to [a Club that describes itself as being } \\
\text { located in one of the "most exclusive" neighborhoods in Mexico } \\
\text { State]... My husband can go during the week, I only go on Sundays. } \\
\text { Are you happy with your current work and family life balance? } \\
\text { Hmmm, I'm not 100\% because I would love to have a flexible schedule } \\
\text { which would allow me to spend more time with my daughter, leave } \\
\text { work with sun light, at 4:00 pm. }\end{array}$ \\
$\begin{array}{l}\text { From fieldwork diary: } \\
\text { It turns out her husband is a partner at another Big Four firm. She } \\
\text { antioned it is common that partners get married to secretaries. Overall, } \\
\text { she spoke positively about the firm. She counts on the support of } \\
\text { domestic help and her mother for household work and child care. }\end{array}$ & \\
\hline
\end{tabular}

The transcripts were reviewed multiple times to reach coding saturation (Charmaz, 2006) and to make sure that all newly-created codes were used in the analysis of all transcripts. In order to increase reliability and accuracy of data interpretation, the second author read the transcripts and proposed new ways of coding and interpreting interviewees' accounts.

As mentioned earlier, our primary goal was to illuminate the construction of intersectional inequality in organizations and how it was experienced by participants. As in earlier intersectional analyses (Pyke, 2010), our focus was not to highlight the frequency of intersections or generalize employees' experiences with career advancement. As such, we only included empirical evidence from the experience of those participants that clearly illuminated these dynamics. Quotes were translated into English after agreement between both authors on how to maintain the Spanish meaning of the text without losing clarity in its English translation. We refer to the Big Four accounting firm as 'BFM' and use pseudonyms for all interviewees.

\section{Findings}


Our findings expose a dynamic and complex picture of inequality at BFM, where gender does not operate as an isolated dimension of difference, but intersects with class, racio-ethnicity and culture in a variety of forms and directions, resulting in specific privileges and disadvantages in the career satisfaction, development and advancement opportunities of its differently socially-located employees (Anthias, 2002). It is not that only a few women are promoted - the traditional gender analysis - but it is light-skinned, attractive and affluentlooking, English-speaking women and men who graduated from private universities and established good relations with the partners, who emerged as the most promotable and careersatisfied at BFM. Next, we discuss in detail our findings, clustered by most important themes.

\section{Gender and the 'not-so-typical' career path}

Career advancement in Mexico, and even participation in paid employment, is a challenge for many Mexican women (Lirio et al., 2007). With minimal enforcement by the Mexican government, only a few employers, usually multinational corporations, implement women's advancement initiatives (Bernal González and Taracena Figueroa, 2012; Brumley, 2013). The few studies conducted on professional women in Mexico show that workplaces are persistently male-dominated and work practices are deeply rooted in notions of masculinity. Under these conditions, women's opportunities for advancement and promotion are scarce (Brumley, 2013, 2014; Ruiz Castro, 2012).

Interview data showed how organizational expectations on career advancement and the appropriate gender roles ascribed, based on women's stage in the life cycle, intersected to stagnate women's career. Career paths at BFM were very well-defined and employees were expected to advance through each echelon of the hierarchical pyramid in specific timeframes (Figure 1.0). Employees usually joined the firm at the staff level at the age of 22 years and reached the senior manager level after about 11 years. They were typically around 36 years old when they were nominated and accepted for partnership. Indeed, as a human resources manager expressed, "It would be suspicious if someone of 37 or 40 years has not been proposed as a partner candidate. It could mean that something has gone wrong in the previous years."

Figure 1.0 "Typical" career path at BFM 


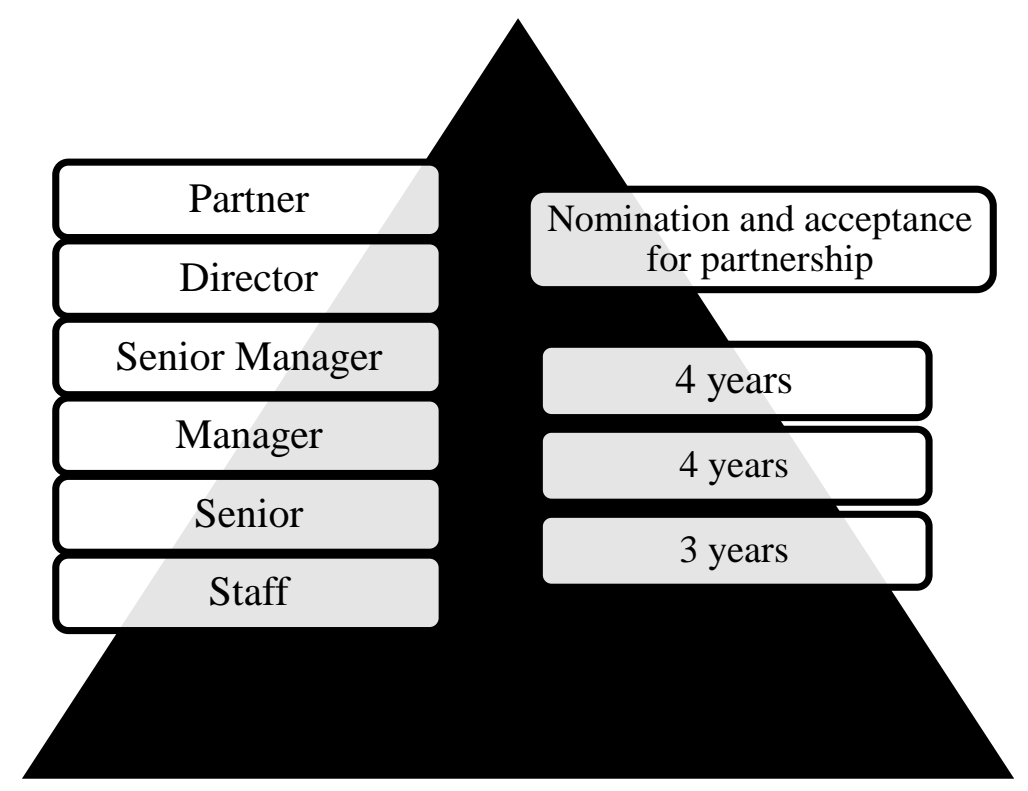

Quantitative data from an employee satisfaction internal survey showed that $66 \%$ of women and $78 \%$ of men agreed with the statement, "I have significant opportunities to advance my career within the firm." In line with this result, 15 out of the 18 male interviewees said they felt satisfied with their career trajectories within the firm and perceived clear advancement opportunities, regardless of their job title and hierarchical status. Most of them affirmed that advancement occurred at a very accelerated pace, especially in the first years of their career:

What is good about the firm is that you can advance; it's difficult to stagnate. There are always problems with moving from the staff to the senior level and from the senior to the manager level... but normally advancement occurs very fast; I'm talking about one year per level. (Ramón, male, staff)

Research shows that despite the fact that women now represent about fifty $50 \%$ of staff members in PSFs, they do not advance to the levels anticipated so as to be considered for partner positions (Kumra and Vinnicombe, 2008). In line with this finding, female interviewees perceived that women did not advance at the same speed or reach top positions as quickly as their male counterparts. They were also less satisfied with their career progression. For some women their career had stagnated at the manager level after 13 or 15 years, while others perceived that it was taking them longer than expected to get a promotion: 
When you reach the last level of the senior position you would expect no more than three years for a promotion to the manager position, but it took me five years instead. (Rebeca, female, manager)

Similarly, Martha, who had been in the firm for two years and had not yet been promoted, was aware of the intersections of her different identities and how these put her at disadvantage:

I'm 30 years old, I'm married and I'm at the senior level. That is not a positive combination because at my age I should already be a manager. My male university colleagues are already managers... The other thing is that I do not have the required English level, and I can understand that this is a problem because [the firm] is international.

According to Martha, mostly men and childless young women were supported by male bosses and, therefore, had the best chances for promotion. Her younger male colleagues were "willing to work very long hours" and "worked hard at being liked by the partner." A younger female colleague also had the best chances for advancement, not only because she was young, single and talented, but also because she had found herself a "godfather."

At home, Martha was committed to her family responsibilities and household chores ("from cooking to washing and ironing"). She also lived in a low-income borough in Mexico City, well-known for its high crime and violence rates, which made it difficult for her to work after regular hours. Martha's experience and profile are a preamble to the importance of the intersections of gender and class at BFM, which prevented some women from advancing their careers when the combination of identities and organizational practices was not 'right.' Women's social location along other dimensions of differences such as racio-ethnicity and class explained the different career experiences among them.

\section{Class markers and practices: Universities, English proficiency, where you live and whom} you live with

Class markers in the Mexican society were found to influence women's and men's advancement opportunities at BFM. One of these markers was the university from which 
employees had graduated ${ }^{3}$. The Mexican educational system is both a manifestation and a perpetuator of the country's polarization between the poor and the rich (Peredo et al., 2007). Working-students from public universities are more likely to work to cover immediate expenses (related to their studies and/or family), whereas those from private universities are more likely to work to gain relevant professional experience and increase their career opportunities (De Garay, 2002). They can earn salaries up to four times as high than graduates from public universities and are more likely to reach top management positions in the private sector (De Vries and Navarro, 2011).

Most of the BFM applicants in Mexico City came from five main universities: one public and four private. Graduates from public universities were described by Human Resources representatives as more suitable for working in the Auditing area, because "those employees who last in Auditing are those 'boys' who want to work hard, whom you can see working on a Sunday." They were perceived as being shy and less confident than graduates from private universities, who were considered to be extroverted and to have leadership skills and a good level of English proficiency. Graduates from private universities were recruited to fill vacancies involving training and specialization in core business areas outside Auditing, which also offered high salaries and good opportunities to participate in the firm's exchange program in US offices.

Increasingly, organizations operating internationally expect their employees to be fluent in English, regardless of their actual location (Heller, 2010; Neeley, 2013). Many workplaces use English proficiency ideologically to construct the 'talented', 'international', and 'global' worker (Park, 2009). In this study, English was not the day-to-day language and many employees did not need it to perform their jobs as they mostly interacted with Mexican colleagues. Nevertheless, English knowledge was a class marker, closely related to employees' public-private university status. Interviewees used this to rationalize constrained advancement opportunities in the firm, especially for women. For example, Ana's male manager told her that the only promotion requirement she needed to fulfill was to improve her English. In her opinion, "this is incongruent, because weeks later they hired a male manager who did not have the English level required for that position and he still does not have it." According to Ana (female, senior), few women managers fulfilled the English proficiency requirement, but she did not see this to be an impediment for male managers. Ana

\footnotetext{
${ }^{3}$ The distinction made here is based on the economic resources required to attend a private University and not the quality of education offered by public and private institutions.
} 
had held the same job position for seven years (she felt "ashamed of even saying it") and was 37 years old, which made it "difficult to convince her supervisors of her potential." She had tried to negotiate with her supervisors to be sent to the US to learn English, a development opportunity offered by the firm, but her request was not considered. Ana was still living with her parents in a low-income area of Mexico City and contributed part of her salary to the household's expenses, both aspects being indicators of her less privileged socio-economic status.

Female interviewees further described cases in which women who carried some markers of a disadvantaged socioeconomic status, including a lack of English proficiency, being morenas $^{4}$ and being financially responsible for her parents and siblings, were mistreated, abused or ignored by the male colleagues and supervisors. As one of the interviewees put it, they simply "do not have any promotion chances" (Cynthia, female, staff).

In contrast, the few women who expressed satisfaction about their trajectories at BFM presented a privileged socio-economic class through high levels of English proficiency, private university degrees, lighter skin color, centrally located homes (which increasingly only the upper classes can afford), household domestic help and participation in expensive leisure activities such as golf. These women were able to take advantage of career advancement and other development opportunities. For example, Yazmín, light-skinned and married to a partner at another Big Four firm, expressed satisfaction with her career at BFM. After a three year break to stay home with her daughter, Yazmín returned to the firm at a higher job level. She was thankful for all the support she had received from her supervisors. She also talked openly about having applied for a job at the firm because of the friendship between her husband and a BFM partner, which seemed to have had a positive impact on her work experience. When asked about her advancement opportunities she said she was "now looking to achieve manager status," for which she needed to improve her English. She hoped to have all the necessary requirements fulfilled by her next evaluation and did not seem disappointed or worried about her advancement opportunities. Yazmín's story points to the intersections of class and racio-ethnicity, which result in career advantages and satisfaction. We explore this in our next theme.

\footnotetext{
${ }^{4}$ Dark-skinned.
} 


\section{Racio-ethnicity markers and appearance: The privilege of whiteness and looking 'pretty' and 'professional'}

All through Latin America the dynamics of racio-ethnic differences support the inseparability of race and ethnicity from dynamics of inequality as experienced in daily life and social structures (Gates, 2011; Hunter, 2002; Villarreal, 2010). Light skin color and European phenotypes are associated with a higher socio-economic status and are key for upward social mobility, especially for the middle and upper classes , "where light complexion seems to be particularly valued" (Flores and Telles, 2012, p. 492). Mexicans use primarily the skin color categories of piel blanca or güero (white skinned or blond), moreno claro (light brown) and moreno oscuro (dark brown) to describe themselves and others in daily life (Villarreal, 2010).

Physical appearance and demeanor are additional sources of status and distinction that determine career opportunities and success in PSFs (Anderson-Gough et al., 2005; Haynes, 2012). As such, these markers were used specifically at BFM to categorize, hierarchize and control both female and male employees. Interviewees' comments referred to the advantage of being perceived as "pretty" and marked as white (like "un arrocito",) and the disadvantage of being marked as dark (like "un frijolito" ${ }^{\text {") }}$ :

Here, part of succeeding is being pretty. That's the reality, that's the image that the firm projects. Let us not fool ourselves. Being pretty is an added advantage. The people who are being supported, they all are pretty. I don't know whether that is a coincidence. But it is evident that if there is un arrocito and a little ugly one, that is, el frijolito, they will choose el arrocito. I think that even when they are equally capable, they will choose the pretty one. (Martha, female, senior)

This was further illustrated by Emilio (male, senior), whose father used to have a blue-collar job. He was planning to "just reach the manager position" (for which he needed to improve his English proficiency) "and then leave the firm". He had been subjected to degrading comments because of having graduated from a public university and for his darkskin complexion, an intersection which carried many disadvantages:

\footnotetext{
${ }^{5}$ Arrocito means a small white grain.

${ }^{6}$ Frijolito means a small black bean.
} 
I had a colleague who graduated from [a private University in Mexico City] and felt superior. He used to tell me "and you what? pinche gato;"7 you are from [a public university in Mexico City]”... Then there is a partner who jokingly tells me, ¿que pasó negro, qué pasó pinche negro? ${ }^{8}$ I only smile... I greet him, "Hello Sir, how are you"... I want to take it just as a game, not as discrimination. But it is indeed uncomfortable.

Interviewees' comments revealed that the more employees were perceived as "pretty" or as members of a higher socio-economic class, the more advantage they had finding "godfathers" and therefore, advancement opportunities. Good-looking, confident and single Violeta was promoted two levels up in one single evaluation (which is rare). She had been sponsored to attend an English course in Canada the previous year and had recently been nominated to participate in the firm's exchange program. She was inclined to take the opportunity despite it posing a conflict with her plans to become a mother because, as she phrased it, participating in the exchange program was a filter: "whoever has been there stays in the firm." For Violeta, both development and advancement opportunities seemed to depend not only on having good relationships with supervisors, but also on her physical appearance (light-skinned and 'professionally' dressed, wearing a formal dark grey suit and a blue blouse), a combination of socio-economic status and racio-ethnic markers.

Women in the professional sector need to utilize impression management techniques in order to find influential sponsors and advance their careers (Kumra and Vinnicombe, 2010). Women, especially, seemed to be valued first in terms of their beauty or lack of it and were forced, directly or indirectly, to adopt the desired standards of appearance. According to the woman partner interviewed, high-potential women were receiving training on personal appearance and business behavior (including make-up, golf and wine-tasting courses).

Sandra, one of the firm's few women senior managers, emphasized that,

One of the most rewarding things that compensate high workloads and long work hours is that the firm has helped me to mature, develop character and even to improve

\footnotetext{
${ }^{7}$ Pinche means a kitchen cleaner. It can be pejorative and used to describe something as insignificant or worthless. It can also be used among friends and family members without being necessarily regarded as an insult. Gato is used in Mexico to refer to people doing the cleaning and other similar low-status jobs.

${ }^{8}$ What's up black guy, what's up pinche black guy? See Footnote 11 for the translation of pinche.
} 
my personal appearance. If you saw me 15 years ago, it has been a radical change in all senses. So I'm very grateful to the firm.

As Sandra's quote demonstrates, within BFM women were socialized into dressing and behaving in certain ways, thereby distancing themselves from stereotypes of gender, racio-ethnicity, and class that ostracize indigenous and poor women in Mexico. This socialization started very early in their careers. For example, two female managers discussed how (male) partners demanded that they ask women staff to change the way they dressed, e.g., from a simple jumper to "a more feminine suit." Another male partner asked that a young woman's employment be terminated because given her appearance, "she could not represent the firm properly." The woman manager who recruited this employee, argued that considering her excellent performance, physical appearance was not enough reason for termination. The young woman remained in the firm but was asked not to visit the partner's office floor. Her appearance was described as "humble," "really long black hair" (a physical trait of most indigenous women), "non-hygienic," and "careless." After some time, "she changed her attitude, started using perfume and became very coqueta. ${ }^{9}$ " When asked whether this employee had gone back to the partner's floor, the manager responded,

No, unfortunately she did not... I feel that was discrimination because of her appearance... The thing is that there are partners; well actually there is everyone, managers, seniors and staff, who are very elitist.

While these findings corroborate the importance of physical appearance in professional services organizations (Haynes, 2012) they also complicate its meaning by showing how appearance intersects not only with gender but also with racio-ethnicity and class in the Mexican context.

\section{Cultural scripts: paternalistic masculinity, 'compadrazgo' and 'respeto'}

As noted earlier, we use the construct of 'cultural scripts' to delineate how cultural expectations, derived from national culture and social understandings about what is 'the right thing to do' in a particular setting, are enacted in this organization. Three 'cultural scripts' seemed most relevant to our analysis of advancement practices at BFM: paternalistic

\footnotetext{
${ }^{9}$ Coqueta means flirtatious.
} 
masculinity/machismo (Holvino, 2010a; Stobbe, 2005); respeto ("granting high regard to persons because of their formal authority, age, or social power" (Holvino, 2010a, p. 10); and compadrazgo [the "exchange of complementary services (favors) performed" within an ideology of friendship and assistance (Lomnitz and Sheinbaum, 2004, p. 8)]. In complex ways, these dominant cultural scripts further increased or decreased the advantages that the 'right mix' of class, gender and racio-ethnic markers represented for career advancement and satisfaction at BFM.

Paternalistic masculinity helped explain the intersections of gender, class and racioethnicity within Mexico's culture dynamics, which advantage men. At BFM, top positions were occupied by men, and as managers and partners in a traditional hierarchical organization, men reproduced the role of the 'father,' who 'controls' family members based on his status (Ruiz Castro, 2012). Employees were expected to be respectful, unquestioningly obedient and loyal. In turn, they were compensated with development and promotion opportunities. For example, Marcos (male, staff), who had been recently promoted, was able to keep a good relationship by not challenging his supervisor's working habits:

There is a lot of compadrazgo... a lot of "you are my friend" and that's how I actually got in the firm. My current manager was my university teacher ... He asked me to work for him and I accepted, but I don't like how he works and how he makes everyone else work... He is arrogant, despotic... If I want to leave the office at 6:00 $\mathrm{pm}$, then he comes and tells me that I have to stay and finish something... He can scold me and ask me to work until 11:00 pm... well, I stay. Even if he does not ask me to stay, I stay. It is this way because of our personal relationship; it is not an employment relationship.

The 'father' was not only controlling, but could also be protective and understanding. Many of the women employees' comments suggested that managers and partners were "considerate" with women who worked hard and who were loyal and respectful. Thus, women's choices were not only "up or out," nor were women being "pushed out" (Stone, 2007). At BFM, women were retained and "appreciated" despite not advancing, for which some interviewees regarded the firm as "good" and "humane." This type of "consideration" that partners and managers showed to women reflected the other and more positive side of the paternalistic masculinity/machismo cultural script that influenced this seemingly benign practice of retention without advancement. 
For example, despite carrying many of the markers that put her in an advantaged career path (light-skinned, master's degree from a prestigious private university and proficient English level), Cynthia (female, staff) did not receive the promotion she expected. She noted that only her male colleagues were promoted and that in contrast to her, they all had "a good relationship with managers and partners". Compadrazgo was clearly intertwined with paternalistic masculinity in that male managers playing the role of "the father" decided who got promoted based on personal relationships.

For women, however, building close relationships with male supervisors was a twosided coin. Keeping distance or maintaining too much respeto was detrimental because women failed to gain the full support of supervisors. Victoria (female, senior manager) told about a male colleague who had followed a very similar career path to hers. He was about to be invited to submit his candidature application to the partners' assembly. When asked why she had not been invited, her first rationalization was that "his English is better than mine." However, she added:

Look, honestly he's a very intelligent person. I think he's handled the relationship with the partners very well, they trust him. I think it's sometimes a matter of personality. For example, I like working, working, working; and sometimes I forget about the relationship with the boss. I have a very good relationship with my partners; they have really supported me a lot... But I've realized that just working and working is not enough; it's also important to relate with others more closely, so they see that you're there."

However, Victoria also recognized that it might be more difficult for her to build close relationships with her partners because "sometimes the male partners draw a line with female managers." In her view, this behavior "is obvious and it is intended to avoid misunderstandings." As a result, she did not address one of her partners by the informal "you," but only by the formal "you,"10 even though he had asked her to do so when she was promoted. She wanted to avoid problems and misinterpretations on his part about sexuality and sexual relations at work. Though the partner had told her that people gossiped that she was too serious, in her view, "a simple smile can be misinterpreted.” Building close relationships with male supervisors could thus be damaging to women's careers, especially

\footnotetext{
${ }^{10}$ In the Spanish language a distinction is made between the formal 'you' (Usted) and the informal 'you' (tú).
} 
for successful young single women, because relationships between men and women became easily sexualized:

We are not going to cover the sun with one finger. There is a lot of "she was promoted because she slept with someone." It has always been like this. I didn't have to go through that, fortunately, and I haven't witnessed that other women got promoted because of that... I was just at the right place at the right time... People say those things about my (male) manager, who supported me a lot... He likes giving kisses and being affectionate with women, but that's the way he is. I don't justify him, but my case wasn't like that... but there are rumors about other women (who have worked with him)... I was seen as one of his favorites and people didn't trust me in the beginning. (Violeta, female, manager)

The above findings suggest that in addition to the masculine-gendered characteristics of the 'ideal worker' - job-focused and unboundedly time-committed (Acker, 1990, 2006b, 2012) - there are also class and racio-ethnic markers that come to function as symbols and identities of power, which co-construct who is valued and rewarded in organizations. Those who carry the desired markers of an ideal hegemonic masculinity are not guaranteed advancement, but rather those symbols and identities become idealized and striven for, exacerbating inequality and advancement disadvantage. At BFM, not everyone who advanced was 'pretty', white, affluent, studied at a prestigious private university or spoke English fluently. Some interviewees described their partners as "obese" or "ill and old-looking" (Ruiz Castro, 2012) and as their stories illustrate, employees at BFM came from a variety of socioeconomic and racio-ethnic backgrounds. Yet, the majority of employees struggled to be seen as having the markers of an affluent socio-economic status and a white racio-ethnic attractiveness and professional demeanor, so as to be perceived as upwardly mobile. While many lacked the markers of privilege, those who reached top positions despite lacking the requirements of the 'idealized professional' were more likely to be male: internal data showed that only $33 \%$ of managers, $12 \%$ of senior managers/directors and only $4 \%$ of partners were women. This reflects the wider society together with its myths and idealizations about the male role, status and embodiment in Mexico. 


\section{Conclusions and implications}

This study responds to the calls for increasing empirical work on the intersections of gender with other social differences in organization studies (Banerjee, 2010; Holvino, 2010b; Muzio and Tomlinson, 2012; Styhre and Eriksson-Zetterquist, 2008; Zander et al., 2010) and for the use of intersectionality as an analytical strategy that does not only pay attention to the topic of work and identity, but also to complex social inequalities within a broader social justice context (Collins, 2015). It also expands on prior work that understands advancement in PSFs as less than meritocratic by showing how intersectional differences and practices contribute to subjective, biased and political career processes and outcomes (Kumra, 2014).

Career trajectories and advancement in the Big Four firm we studied did not follow a rational series of progressive and teachable steps that women and men could follow, but instead seemed fairly random and contradictory processes, over-determined by individual employees' identities, work interactions shaped by those identities, as well as formal and informal organizational practices embedded in an already raced, classed and gendered societal context and culture.

The contribution of our analysis is threefold. Conceptually, 'simultaneity' (Holvino, 2010b, 2012), as an intersectional approach in organization studies served as a useful approach to re-analyze career advancement practices in this Big Four firm. By focusing on the relationship between identities, organizational, and societal practices we showed how advantage and disadvantages were co-constructed through specific practices of career development and advancement, which derived their meanings and were co-constituted in relation to cultural and societal discourses and structures of differences.

We advance intersectional research in organizations by applying the constructs of 'markers of inequality' and 'cultural scripts' to study how differences of gender, class and racio-ethnicity are culturally constructed within the specific socio-cultural context of this Mexican firm. Our analysis confirms that social differences like racio-ethnicity and class need not be defined externally and a priori, but that instead, attending to specific 'markers of inequality,' derived from both the literature and interviewees' particular experiences, can help better identify and understand organizational inequalities, especially in global organizations where the meanings of social differences are not universal. In addition, the use of 'cultural scripts' facilitates noticing the ways in which socio-cultural norms and expectations intersect and influence organizational practices and inequality outcomes and serve as societal discourses that legitimate inequality regimes. 
At the methodological level, our work also contributes to advancing empirical research on intersectionality in organizations by affirming the importance of an 'intersectional sensibility' in the analysis of data rather than on collecting the 'right' categories of data (Bowleg, 2008; Crenshaw, 1991; Healy et al., 2011). Contrary to Acker's (2010) idea that without research questions with an a priori focus on intersections, "the least visible manifestations of class, race and gender processes may remain invisible" (p. 220), our study suggests that it is possible to use qualitative data initially collected with the purpose of studying gendered processes in organizations, if for example, 'markers of inequality' are systematically identified in the analysis. This highlights one advantage of qualitative research for intersectional studies as it may be possible to re-analyze empirical data to generate new insights about advancement practices (and other dimensions of inequality regimes) using an intersectional sensibility, even when the original analysis was not an intersectional one. This augurs well for re-visioning prior studies focused only on gender through an intersectional lens so as to enrich our understanding of inequality in organizations (Benschop \& Doorewaard, 2012)

Lastly, because change and social justice are at the core of intersectionality as a political project, we identify a potential contribution to the practice of organizational change. Since the intersections of gender, class and racio-ethnicity are embedded in culture and are not fixed or universal, but dynamic and specific to time and place, it is essential to study these differences in their geo-political and cultural contexts in order to design appropriate change interventions. Multinational corporations increasingly transfer initiatives on career advancement from their Global North headquarters to their subsidiaries in the Global South. We join prior critiques that call attention to the dangers of uncritically importing 'best practices' such as 'diversity initiatives' from one socio-economic and cultural context into another, without taking into account how differences intersect in different ways and may have different meanings in different contexts (Poster, 2008; Walgenbach and Hegele, 2001). At BFM, compadrazgo helped certain individuals to advance their careers, but this should not be confused with 'mentoring' or 'networking' initiatives commonly implemented in Global North countries. Even if Mexican employees participate in formal mentoring initiatives to help them advance their careers, the intersections of gender, class and racio-ethnic markers and cultural scripts like paternalistic masculinity/machismo and compadrazgo might be more influential in determining their advancement opportunities.

Our study also points to important limitations and areas of future research. Given our single case study approach, neither our findings nor conclusions are generalizable to all PSFs, 
industries, organizational structures and cultures, even within the Mexican context. Moving forward, our framework and methodological approach can be applied in other organizations and geo-political contexts to identify complex inequalities, yet, more work is needed in order to translate these analyses into practical recommendations for organizational change to eliminate those inequalities.

Another future direction is the use of 'cultural scripts' as a tool to identify sociocultural dynamics that complicate how differences in organizations intersect, collide, reinforce each other, but also converge and mix with macro-structures (Pieterse, 2009), particularly in multinational corporations pursuing neoliberal economic and globalizing agendas in Global South countries.

We are encouraged by the possibilities of applying intersectional sensibilities and frameworks to the study of inequality and differences in organizations in the ubiquitous context of globalization. 


\section{References}

Acker, J. (1990) Hierarchies, jobs, bodies: A theory of gendered organizations. Gender \& Society, 4,2, 139-158.

Acker, J. (1992) Gendering organizational theory. In A. J. Mills \& P. Tancred (Eds.), Gendering organizational theory. Thousand Oaks, CA: Sage.

Acker, J. (2006a) Class questions: Feminist answers: Altamira Press.

Acker, J. (2006b) Inequality regimes gender, class, and race in organizations. Gender \& Society, 20,4, 441-464.

Acker, J. (2011) Theorizing gender, race, and class in organizations. Handbook of Gender, Work and Organization, 65-80.

Acker, J. (2012) Gendered organizations and intersectionality: problems and possibilities. Equality, Diversity and Inclusion: An International Journal, 31,3, 214-224.

Anderson-Gough, F., Grey, C. and Robson, K. (2005) "Helping them to forget..": the organizational embedding of gender relations in public audit firms. Accounting, Organizations and Society, 30,5, 469-490.

Annisette, M. (2003) The colour of accountancy: examining the salience of race in a professionalisation project. Accounting, Organizations and Society, 28,7, 639-674.

Anthias, F. (2002) Beyond feminism and multiculturalism: Locating difference and the politics of location. In Women's Studies International Forum, 25,3, 275-286.

Anthias, F. (2013) Intersectional what? Social divisions, intersectionality and levels of analysis. Ethnicities, 13,1, 3-19.

Antonucci, T. C., Birditt, K. S. and Ajrouch, K. J. (2011) Convoys of social relations: past, present and future. In K. L. Fingerman, C. Berg, J. Smith and T. C. Antonucci (Eds.), Handbook of Life-Span Development (161-182) New York: Springer.

Atewologun, D. and Sealy, R. (2014) Experiencing privilege at ethnic, gender and senior intersections. Journal of Managerial Psychology, 29,4, 423-439.

Banerjee, P. (2010) The Burgeoning Field of Gender, Work \& Organization: Some thoughts on the 6th Biennial International Conference of the journal Gender, Work and Organisation (GWO2010) Paper presented at the Gender Work and Organizations Online Conference Proceedings.

Bell, E. L. E. and Nkomo, S. M. (2003) Our separate ways: Black and white women and the struggle for professional identity: Harvard Business Press.

Benschop, Y. and Doorewaard, H. (2012) Gender subtext revisited. Equality, Diversity and Inclusion: An International Journal, 31,3, 225-235.

Bernal González, M. C. and Taracena Figueroa, E. (2012) Talento Femenino en la Alta Dirección en México. Mexico: LID.

Boogaard, B. and Roggeband, C. (2010) Paradoxes of intersectionality: Theorizing inequality in the Dutch police force through structure and agency.Organization, 17,1, 53-75.

Bowleg, L. (2008) When Black+ lesbian+ woman $\neq$ Black lesbian woman: The methodological challenges of qualitative and quantitative intersectionality research. Sex Roles, 59,5-6, 312-325.

Bowleg, L. (2012) The problem with the phrase women and minorities: intersectionality-an important theoretical framework for public health. American Journal of Public Health, 102,7, 1267-1273.

Bowleg, L., Lucas, K. J. and Tschann, J. M. (2004) "The ball was always in his court": An exploratory analysis of relationship scripts, sexual scripts, and condom use among African American women. Psychology of Women Quarterly, 28,1, 70-82.

Broadbent, J. and Kirkham, L. (2008) Glass ceilings, glass cliffs or new worlds?: Revisiting gender and accounting. Accounting, Auditing \&Accountability Journal, 21,4, 465-473. 
Brown, P. (1995) Cultural capital and social exclusion: some observations on recent trends in education, employment and the labour market. Work, Employment \& Society, 9, 1, 2951.

Brumley, K. M. (2013) “It Was Like a Revolution”: Women's Perceptions of Work-Family Practices at a Mexican Multinational Corporation. Journal of Family Issues, 35,6, 776-807.

Brumley, K. M. (2014) 'Now, We Have the Same Rights as Men to Keep Our Jobs': Gendered Perceptions of Opportunity and Obstacles in a Mexican Workplace. Gender, Work \& Organization, 21,3, 217-230.

Calás, M. B. (1992) An/other silent voice? Representing "Hispanic woman" in organizational texts. Gendering organizational analysis, 201-221.

Calás, M. B., Smircich, L. and Holvino, E. (2014) Theorizing Gender and Organization: Changing Times, Changing Theories. In S. Kumra, R. Simpson \& R. J. Burke (Eds.), The Oxford handbook of Gender in Organizations (17-52) Oxford: Oxford University Press.

Charmaz, K. (2006) Constructing grounded theory: A practical guide through qualitative research. London: SAGE Publications.

Cho, S., Crenshaw, K. W. and McCall, L. (2013) Toward a field of intersectionality studies: Theory, applications, and praxis. Signs, 38,4, 785-810.

Choo, H. Y. and Ferree, M. M. (2010) Practicing Intersectionality in Sociological Research: A Critical Analysis of Inclusions, Interactions, and Institutions in the Study of Inequalities. Sociological Theory, 28,2, 129-149.

Collins, P. H. (2000) Black feminist thought: Knowledge, consciousness and politics of empowerment: Psychology Press.

Collins, P. H. (2015) Intersectionality's Definitional Dilemmas. Annual Review of Sociology, 41, 1-20.

Crenshaw, K. (1989) Demarginalizing the intersection of race and sex: A Black feminist critique of antidiscrimination doctrine, feminist theory and antiracist politics. U. Chi. Legal F., 139.

Crenshaw, K. (1991) Mapping the margins: Intersectionality, identity politics, and violence against women of color. Stanford law review, 1241-1299.

Crenshaw, K. (2011) Postscript. In H. Lutz, M. T. H. Vivar \& L. Supik (Eds.), Framing intersectionality: Debates on a multi-faceted concept in gender studies: Ashgate Publishing, Ltd.

Dambrin, C. and Lambert, C. (2008) Mothering or auditing? The case of two Big Four in France. Accounting, Auditing \& Accountability Journal, 21,4,, 474-506.

Davis, K. (2008) Intersectionality as buzzword. Feminist theory, 9, 1, 67-85.

De Garay, A. (2002) Un sistema de educación superior, dos realidades distintas: la universidad pública y la universidad privada. Revista de la educación superior, 31,1, 69-78.

De Vries, W. and Navarro, Y. (2011) ¿Profesionistas del futuro o futuros taxistas? Los egresados universitarios y el mercado laboral en México. Revista Iberoamericana de Educación Superior, 2,4.

Dhamoon, R. K. (2011) Considerations on mainstreaming intersectionality. Political Research Quarterly, 64,1, 230-243.

Dhingra, P. (2007) Managing multicultural lives: Asian American professionals and the challenge of multiple identities: Stanford University Press.

Duff, A., 2011. Big four accounting firms' annual reviews: A photo analysis of gender and race portrayals. Critical Perspectives on Accounting, 22,1, 20-38. 
Fearfull, A. and Kamenou, N. (2006) How do you account for it?: A critical exploration of career opportunities for and experiences of ethnic minority women. Critical Perspectives on Accounting, 17,7, 883-901.

Fernández-Kelly, P. (2004) The Future of Gender in Mexico and the United States: Economic Transformation and Changing Definitions. Research in Social Stratification and Mobility, 22, 255-280.

Fernández-Kelly, P. (2005) Reforming gender: the effects of economic change on masculinity and femininity in Mexico and the US. Women's Studies, 69.

Fernández-Kelly, P. (2008) Gender and economic change in the United States and Mexico, 1900-2000. American Behavioral Scientist, 52,3, 377-404.

Flores, R. and Telles, E. (2012) Social Stratification in Mexico Disentangling Color, Ethnicity, and Class. American Sociological Review, 77,3, 486-494.

Gates, H. L. (2011) Black in Latin America: NYU Press.

Giscombe, K. (2008) Women of Color in Accounting Women of Color in Professional Services Series: Catalyst.

Hammond, T. (2003) History from accounting's margins: international research on race and gender. Accounting History, 8,1, 9-24.

Haynes, K. (2008) Transforming identities: accounting professionals and the transition to motherhood. Critical Perspectives on Accounting, 19,5, 620-642.

Haynes, K. (2012) Body beautiful? Gender, identity and the body in professional services firms. Gender, Work \& Organization, 19,5, 489-507.

Healy, G., Bradley, H. and Forson, C. (2011) Intersectional sensibilities in analysing inequality regimes in public sector organizations. Gender, Work\& Organization, 18,5, 467-487.

Heller, M. (2010) Language as Resource in the Globalized New Economy. The handbook of language and globalization, 58, 349-365.

Holvino, E. (2000) Class and Gender in Organizations. CGO Insights No. 7. Boston: Center for Gender in Organizations, Simmons School of Management.

Holvino, E. (2003) Theories of differences: Changing paradigms for organizations. Handbook of Diversity Management: Beyond Awareness to Competency Based Learning. Lanham, MD: University Press of America, 111-132.

Holvino, E. (2010a) "I think it's a cultural thing and a woman thing:" Cultural scripts in Latinas' careers. CGO Insights, 30.

Holvino, E. (2010b) Intersections: the simultaneity of race, gender and class in organization studies. Gender, Work \& Organization, 17, 3, 248-277.

Holvino, E. (2012) Time, space and social justice in the age of globalization: Research and applications on the simultaneity of differences Practising social change(5).

Hulko, W. (2009) The time-and context-contingent nature of intersectionality and interlocking oppressions. Affilia, 24,1, 44-55.

Smith, B., Hull, G. T. and Scott, P. B. (Eds.) (1982) All the Women Are White, All the Blacks Are Men, But Some of Us Are Brave: Black Women's Studies. Feminist Press.

Hunter, M. L. (2002) "If You're Light You're Alright" Light Skin Color as Social Capital for Women of Color. Gender \& Society, 16,2, 175-193.

Hunting, G. (2014) Intersectionality-informed Qualitative Research: A primer. Vancouver, BC: The Institute of Intersectionality Research and Policy. Simon Fraser University.

Jacobs, K. (2003) Class reproduction in professional recruitment: examining the accounting profession. Critical Perspectives on Accounting, 14,5,569-596.

James, K. and Otsuka, S. (2009) Racial biases in recruitment by accounting firms: the case of international Chinese applicants in Australia. Critical Perspectives on Accounting, 20,4, 469-491. 
Jonnergård, K., Stafsudd, A. and Elg, U. (2010) Performance evaluations as gender barriers in professional organizations: a study of auditing firms. Gender, Work \& Organization, 17,6, 721-747.

Kelan, E. K. (2014) From Biological Clocks to Unspeakable Inequalities: The Intersectional Positioning of Young Professionals. British Journal of Management, 25,4, 790-804.

Kim, S. N. (2004) Racialized gendering of the accountancy profession: toward an understanding of Chinese women's experiences in accountancy in New Zealand. Critical Perspectives on Accounting, 15,3, 400-427.

Knudsen, S. V. (2006) Intersectionality-a theoretical inspiration in the analysis of minority cultures and identities in textbooks. Caught inthe Web or Lost in the Textbook, 61-76.

Kornberger, M., Carter, C. and Ross-Smith, A. (2010) Changing gender domination in a Big Four accounting firm: Flexibility, performance and client service in practice. Accounting, Organizations and Society, 35,8, 775-791.

Kumra, S. (2014) Gender Constructions of Merit and Impression Management within Professional Services Firms. In S. Kumra, R. Simpson \& R. J. Burke (Eds.), The Oxford handbook of Gender in Organizations (269-291). Oxford: Oxford University Press.

Kumra, S. and Vinnicombe, S. (2008) A study of the promotion to partner process in a professional services firm: how women are disadvantaged. British Journal of Management, 19,1, 65-74.

Kumra, S. and Vinnicombe, S. (2010) Impressing for success: a gendered analysis of a key social capital accumulation strategy. Gender, Work \& Organization, 17,5, 521-546.

Law, P. and Yuen, D. (2011) An empirical examination of hiring decisions of experienced auditors in public accounting: Evidence from Hong Kong. Managerial Auditing Journal, 26,9, 760-777.

Lirio, P., Lituchy, T. R., Monserrat, S. I., Olivas-Lujan, M. R., Duffy, J. A., Fox, S., Gregory, A., Punnett, B. J. and Santos, N. (2007) Exploring career-life success and family social support of successful women in Canada, Argentina and Mexico. CareerDevelopment International, 12,1, 28-50.

Lomnitz, L. A. and Sheinbaum, D. (2004) Trust, Social Networks and the Informal Economy: A Comparative Analysis. Review of Sociology, 10,1, 5-26.

Loury, G. C. (2009) The anatomy of racial inequality: Harvard University Press.

Lowe, D. J., Reckers, P. M. and Sanders, D. (2001) The influence of gender, ethnicity, and individual differences on perceptions of career progression in public accounting. International Journal of Auditing, 5,1, 53-71.

Martin, P. Y. and Turner, B. A. (1986) Grounded theory and organizational research. The Journal of applied behavioral science, 22,2, 141-157.

McBride, A., Hebson, G. and Holgate, J. (2015) Intersectionality: are we taking enough notice in the field of work and employment relations?. Work, Employment \& Society, 29,2, 331-341.

McCall, L. (2005) The complexity of intersectionality. Signs, 30,3, 1771-1800.

Muzio, D. and Tomlinson, J. (2012) Editorial: Researching Gender, Inclusion and Diversity in Contemporary Professions and Professional Organizations. Gender, Work\& Organization, 19,5, 455-466.

Neeley, T. B. (2013) Language matters: Status loss and achieved status distinctions in global organizations. Organization Science, 24,2, 476-497.

Nkomo, S. M. and Stewart, M. M. (2006) Diverse identities in organizations. In S. R. Clegg, C. Hardy, T. B. Lawrence \& W. R. Nord (Eds.), The SAGE Handbook of Organization Studies (520-541) London: SAGE Publications 
Park, J. S. (2009) The local construction of a global language: Ideologies of English in South Korea (Vol. 24): Walter de Gruyter.

Peredo, N. G. E., De la Paz Ortega, M. and Antón, M. G. (2007) De “¿cuál te pinta mejor?” a “¿para cuál te alcanza?”: Desigualdad e inequidad social en el acceso a la educación superior en México. Revista Electrónica de Investigación Educativa, 9,1.

Phoenix, A. and Pattynama, P. (2006) Intersectionality. European Journal of Women's Studies, 13,3, 187-192.

Pieterse, J. N. (2009) Globalization and culture: Global mélange: Rowman \& Littlefield Publishers.

Portwood, D. and Fielding, A. (1981) Privilege and the Professions. The Sociological Review, 29,4, 749-773.

Poster, W. R. (2008) Filtering Diversity A Global Corporation Struggles With Race, Class, and Gender in Employment Policy. American Behavioral Scientist, 52,3, 307-341.

Pringle, J. K. (2008) Gender in management: theorizing gender as heterogender. British Journal of Management, 19,1, 110-119.

Purkayastha, B. (2012) Intersectionality in a Transnational World. Gender \& Society, 26,1, $55-66$.

Pyke, K. (2010) An intersectional approach to resistance and complicity: The case of racialised desire among Asian American women. Journal of Intercultural Studies, 31,1, 81-94.

Reay, D., Davies, J., David, M. and Ball, S. J. (2001) Choices of degree or degrees of choice? Class, 'race' and the higher education choice process. Sociology, 35,4, 855-874.

Ruiz Castro, M. (2012) Time Demands and Gender Roles: The Case of a Big Four Firm in Mexico. Gender, Work \& Organization, 19,5, 532-554.

Scully, M. and Blake-Beard, S. (2006) Locating class in organizational diversity work. Handbook of workplace diversity, 431-453.

Simien, E. M. (2007) Doing intersectionality research: From conceptual issues to practical examples. Politics \& Gender, 3,2, 264-271.

Steyaert, C. and Janssens, M. (2013) Multilingual scholarship and the paradox of translation and language in management and organization studies. Organization, 20,1, 131-142.

Stobbe, L. (2005) Doing machismo: legitimating speech acts as a selection discourse. Gender, Work \& Organization, 12,2, 105-123.

Stone, P. (2007) Opting out?: Why women really quit careers and head home: Univ of California Press.

Styhre, A. and Eriksson-Zetterquist, U. (2008) Thinking the multiple in gender and diversity studies: examining the concept of intersectionality. Gender in Management: An International Journal, 23,8, 567-582.

Sue, D. W. (2006) The Invisible Whiteness of Being: Whiteness, White Supremacy, White Privilege, and Racism. In Constantine, M. G. and Sue, D. W. (Eds.) Addressing racism: Facilitating cultural competence in mental health and educational settings (15-30). New York: John Wiley \& Sons.

Tatli, A. and Özbilgin, M. F. (2012) An emic approach to intersectional study of diversity at work: a bourdieuan framing. International Journal of Management Reviews, 14,2, 180-200.

Thomson, D., Bzdel, L., Golden-Biddle, K., Reay, T. and Estabrooks, C. A. (2005) Central questions of anonymization: A case study of secondary use of qualitative data. Forum Qualitative Sozialforschung/Forum: Qualitative Social Research, 6,1.

Townsend-Bell, E. (2011) What is Relevance? Defining Intersectional Praxis in Uruguay. Political Research Quarterly, 64,1, 187-199. 
Valentine, G. (2007) Theorizing and Researching Intersectionality: A Challenge for Feminist Geography. The Professional Geographer, 59,1, 10-21.

Van den Berg, H. (2008) Reanalyzing qualitative interviews from different angles: The risk of decontextualization and other problems of sharing qualitative data. Historical Social Research/Historische Sozialforschung, 179-192.

Villarreal, A. (2010) Stratification by skin color in contemporary Mexico. American Sociological Review, 75,5, 652-678.

Villarreal, A. and Yu, W. (2007) Economic globalization and women's employment: the case of manufacturing in Mexico. American Sociological Review, 72,3, 365-389.

Walgenbach, P. and Hegele, C. (2001) What can an apple learn from an orange? Or: what do companies use benchmarking for? Organization, 8,1, 121-144.

Walsh, I., Holton, J. A., Bailyn, L., Fernandez, W., Levina, N. and Glaser, B. (2015) What Grounded Theory Is... A Critically Reflective Conversation Among Scholars. Organizational Research Methods, 18,4, 581-599.

Warner, L. R. (2008) A best practices guide to intersectional approaches in psychological research. Sex roles, 59,5-6, 454-463.

Weber, L. (2010) Understanding Race, Class, Gender and Sexuality: A Conceptual Framework (2nd ed.). New York: Oxford University Press.

Weinbaum, B. (1983) Pictures of Patriarchy. Boston: South End Press.

Weisenfeld, L. and Robinson-Backmon, I. (2001) Minority accountants' views on gender and race biases, career limitations and suggestions for undergraduate educational institutions. Journal of Accounting Education, 19,3, 163-187.

Whiting, R. H. (2008) The Determinants of Career Success in the New Zealand Accountancy Profession (Accountancy Working Paper Series No. 8). Paper presented at the EIASM 23rd Workshop on Strategic Human Resource Management, Slovenia.

Windsor, C. and Auyeung, P. (2006) The effect of gender and dependent children on professional accountants' career progression. Critical Perspectives on Accounting, $17,6,828-844$.

Winker, G. and Degele, N. (2011) Intersectionality as multi-level analysis: Dealing with social inequality. European Journal of Women's Studies, 18,1, 51-66.

Zander, U., Zander, L., Gaffney, S. and Olsson, J. (2010) Intersectionality as a new perspective in international business research. Scandinavian Journal of Management, 26,4, 457-466. 